\title{
REPRESENTAÇÕES SOCIAIS DE PROFESSORES DE UMA ESCOLA PÚBLICA DE ENSINO FUNDAMENTAL: OBJETIVOS PARA UM PROJETO EM EDUCAÇÃO AMBIENTAL
}

Jacson Luís Reiniak ${ }^{1}$

Nelma Baldin²

lana Gomes de Lima ${ }^{3}$

Resumo: Este artigo é um recorte de uma dissertação de mestrado em educação e têm como objetivo evidenciar as Representações Sociais que os professores de uma escola pública de ensino fundamental no município de Joinville - SC possuem quanto aos "objetivos a serem trabalhados na Educação Ambiental'. No âmbito metodológico, contou-se com as respostas de dez professores, à questão: "Imaginemos que a escola (comunidade escolar) busque sua ajuda para elaboração de uma atividade sobre Educação Ambiental junto aos alunos. O que você proporia como objetivo(s)?". As respostas, interpretadas conforme o método da análise de conteúdo (BARDIN, 2016), permitiram a obtenção das categorias representacionais: "ambiental", "cultural", "ação pedagógica" e "lixo".

Palavras-chave: Educação Ambiental; Representações Sociais; Escola Pública.

1 Univille. E-mail: jacsonIr@yahoo.com.br

2 UFSC. E-mail: nelmabaldin47@gmail.com

3 Univille. E-mail: iana_glima@yahoo.com.br 


\section{Introdução}

Este artigo tem por objetivo evidenciar as Representações Sociais que os professores de uma escola pública de ensino fundamental no município de Joinville - SC possuem quanto aos "objetivos a serem trabalhados na Educação Ambiental'.

Segundo Moscovici (2015), as representações sociais permitem um olhar profundo sobre os construtos conceituais socialmente construídos e, por conseguinte, sobre a ação prática reproduzida pelos sujeitos. Compreender as representações sociais é ter acesso às ideias, crenças, estruturas produtoras dos saberes, as relações que se estabelecem em torno delas e da manifestação deste conteúdo na prática, além das transformações das representações pela prática. Em outras palavras, nossas ações são orientadas pelas representações que temos e o mundo, por sua vez, refaz permanentemente as representações que possuímos a ponto de um se tornar o outro na familiaridade, considerando, como se lê em Moscovici (2015, p. 74), que "isso acontece na medida em que a distinção entre imagem e realidade são esquecidas".

O nosso pensamento é como um ambiente habitado por palavras, ideias e imagens. Nesse sentido, os sujeitos sociais constroem suas relações e dão sentido ao mundo pelos significados.

De um lado, é através de sua atividade e relação com outros que as representações têm origem, permitindo uma mediação entre o sujeito e o mundo que ele ao mesmo tempo descobre e constrói. De outro lado, as representações permitem a existência de símbolos (...). É sobre e dentro de uma rede de significados que se dão os trabalhos do sujeito de recriar o que já está lá. O sujeito psíquico, portanto, não está abstraído da realidade social, nem meramente condenado a reproduzi-la. Sua tarefa é elaborar a permanente tensão entre o mundo que já se encontra constituído e seus próprios esforços para ser um sujeito (JOVCHELOVITCH, 1995, p. 78).

O sujeito não é determinado pelos fatores sociais externos a ele, nem se encontra em um plano separado do fenômeno social. Nesse sentido, o sujeito é entendido como um promotor de tensões entre o mundo socialmente constituído e os dados subjetivos pertencentes a ele. As representações sociais intervêm no processo cognitivo dos sujeitos na medida em que

convencionalizam os objetos, pessoas ou acontecimentos que encontram. Elas Ihes dão uma forma definida, as localizam em uma determinada categoria e gradualmente as colocam como um modelo de determinado tipo, distinto e partilhado por um grupo de pessoas [...]. 
As representações são prescritivas, isto é, elas se impõem sobre nós como uma força irresistível. Essa força é uma combinação de uma estrutura que está presente antes mesmo que nós comecemos a pensar e de uma tradição que decreta 0 que deve ser pensado (MOSCOVICI, 2015, p. 34-36).

As representações possuem vida própria e se relacionam para produzir novos sentidos ao longo do curso de sua existência. A dinâmica das representações sociais acontece pelo fato delas estarem presentes e formarem a sociedade por via da comunicação. Ao pensar sobre os espaços onde ocorrem a comunicação na sociedade, observamos que só existe a sociedade por conta da comunicação, o que torna redundante pensar a sociedade e comunicação como esferas próximas, haja vista só haver a sociedade por conta da comunicação existente entre os sujeitos pertencentes a ela. As arenas mais comuns para difusão dos valores, dos embates entre diferentes ideias, da disseminação do senso comum e que permitem a circulação das representações são: a escola, espaços públicos abertos, igrejas, locais de encontro para recreação e lazer, entre outros.

O "mirante" sobre o qual o professor é posicionado ou se posiciona para compreender um fenômeno específico ao mesmo tempo que revela as "verdades" sobre o objeto, também limita ou define o objeto a uma perspectiva assumida a priori. Freire (1997, p. 47) fala que é preciso que o professor assuma uma posição mais elevada para que sua perspectiva não seja a de uma cabeça baixa. Neste sentido, as representações sociais permitem o levantamento dos "mirantes" teóricos, éticos, políticos, enfim, dos fundamentos culturais presentes na sustentação da compreensão de mundo dos pesquisados.

Neste artigo, um grupo específico de dez professores de uma escola pública municipal foi colocado como foco de estudo. Por via da obtenção de suas representações sociais, buscou-se encontrar, também, os fundamentos epistemológicos, éticos e estéticos que repercutem em suas mais diversas práticas. Desta forma, a Teoria das Representações Sociais é uma forte aliada no estudo dos atores sociais e suas condutas, possibilitando uma compreensão profunda e abrangente do fenômeno investigado. A aplicação da Teoria das Representações Sociais no ambiente escolar, especialmente junto aos professores, permite a revelação dos conteúdos socialmente desenvolvidos e que se manifestam nas práticas cotidianas automatizadas. Em outras palavras, práticas cristalizadas no meio social.

Nesse sentido, a busca pelas representações sociais sobre quais os "objetivos a serem trabalhados na Educação Ambiental" é uma valiosa atividade no campo da pesquisa educacional por possibilitar a compreensão do fenômeno humano em seu processo de assimilação dos códigos sociais e da leitura de mundo advinda deles. Evidenciar essas representações sociais contribuirá, consequentemente, no entendimento do alcance que a temática ambiental 
possui no repertório conceitual dos professores pesquisados. Sendo a prática de ensino estreitamente ligada às concepções que o educador possui, as representações sociais que os professores possuem orientarão o caminho trilhado por eles no campo da Educação Ambiental junto a seus estudantes.

A escola fundamental é um espaço privilegiado de formação das representações sociais. Primeiramente, pela diversidade dos sujeitos envolvidos no processo educativo, os quais trazem consigo suas experiências de vida e que pela relação face a face produzem novos conteúdos e significados. Pela relação - troca de experiências - a humanidade é formada e orientada. Em segundo lugar, a escola é campo da difusão dos conteúdos culturais política e hegemonicamente produzidos. Os sujeitos envolvidos no processo educativo e os conteúdos evidenciados no currículo escolar tecem a trama da educação escolar.

Pensar a educação escolar na perspectiva dos objetivos para a Educação Ambiental é, de fato, refletir sobre as forças exercidas sobre a sociedade com a intenção de contemplar alguns conteúdos e acobertar outros pouco interessantes. Cabe lembrar que esses juízos de valor não são neutros, sempre há uma intenção política.

A Educação Ambiental envolve questões complexas e que dizem respeito a vários setores e conceitos presentes na sociedade, tais como: a política, a economia, os valores, a concepção de ser humano, o mundo natural, entre outros componentes que, por via de uma abordagem interdisciplinar se tornam acessíveis e de modo mais amplo ao estudante (REIGOTA, 2014).

Nesta linha de raciocínio, entende-se que as representações sociais que são manifestadas pelos professores da educação fundamental pública revelam mais que conteúdos científicos somados a elementos do senso comum. São aproximações a discursos superficiais e alienantes de ideologias subterraneamente formadas ou distanciadas desses discursos para a busca da crítica à ideologia visando a ascensão da subjetividade humana integrada ao meio ambiente (MOSCOVICI, 2015).

\section{Metodologia}

A pesquisa aqui em realce aconteceu em uma escola pública de ensino fundamental na cidade de Joinville - SC. Fundada em 09 de março de $1851 \mathrm{com}$ a chegada dos primeiros imigrantes europeus, Joinville situa-se ao norte do Estado de Santa Catarina. A cidade conta com uma área de $1.126,106 \mathrm{~km}^{2} \mathrm{e}$ uma população de aproximadamente 562.151 habitantes, segundo dados da última pesquisa ali realizada (IBGE, 2015).

Os dados coletados durante a aplicação da pesquisa foram trabalhados conforme as características da análise de conteúdo (BARDIN, 2016) e seguem uma abordagem qualitativa. Por meio da observação de campo, das anotações no Caderno de Campo, do estudo dos documentos escolares (PPP) e da 
aplicação de um roteiro de questões, respondido pelos dez professores participantes da pesquisa e cujas respostas à questão "Imaginemos que a escola (comunidade escolar) busque sua ajuda para elaboração de uma atividade sobre Educação Ambiental junto aos alunos. O que você proporia como objetivo(s)?' serviram de base material para a elaboração deste artigo. Pretendeu-se, com esse procedimento, obter suas representações sociais sobre os objetivos da Educação Ambiental para o ensino fundamental.

Para a análise dos dados obtidos com essa questão em específico, optou-se por um sistema de categorização a posteriori. Conforme orienta Bardin (2016), para a formação dos títulos conceituais de cada categoria foram consideradas as palavras mais "fortes", ou seja, acatou-se as palavras mais repetidas pelos (as) participantes nas respostas à questão. Em outras palavras, considerou-se a recorrência das palavras. As categorias representacionais foram definidas somente ao término da operação de análise e interpretação. Estas também foram confrontadas com a base teórica de Educação Ambiental produzida nacionalmente.

As respostas à questão trabalhada neste artigo foram transcritas pelo pesquisador com possíveis adaptações, no intuito de adequar a escrita, sem prejuízo ao sentido que o participante pretendeu dar em suas respostas. Estimulados a responder o mais "completo" possível, os (as) professores (as) aqui identificados (as) como D1, D2, D3 e assim por diante até D10 -, revelaram o que entendem por "Objetivos para a Educação Ambiental" para a escola de ensino fundamental, os temas que devem ser trabalhados sobre essa temática, a formação humana necessária para a formação de um mundo sustentável, onde a Educação Ambiental deve ser trabalhada, a perspectiva teleológica do trabalho docente com a Educação Ambiental e, ainda, sobre projetos de Educação Ambiental. Com o levantamento do que pensam os professores, apresentou-se a possibilidade de elaborar um conceito geral por via de um exercício de abstração e síntese dos conteúdos evocados nas proposições então redigidas.

Os depoimentos dos docentes expresso nas respostas à questão apresentada e as anotações no Caderno de Campo do pesquisador foram considerados itens importantes na formulação das análises e interpretação das proposições. Sendo assim, a questão proposta, mais as manifestações dos participantes e os conteúdos obtidos com a observação da escola (ambiente físico e as aulas) foram devidamente registradas no Caderno de Campo do pesquisador e agregaram valor à pesquisa, principalmente por pluralizar os instrumentos de coleta de dados. No entanto, não só os instrumentos de coleta de dados são plurais nesta pesquisa, a análise dos dados por via de análise temática a recorrência de palavras e interpretação das observações de campo favoreceram a uma aproximação mais efetiva do real que se manifesta nas representações sociais sobre os temas trabalhados no estudo. Neste sentido, Bardin (2016) afirma que o trabalho realizado ao empregar as técnicas da análise de conteúdo produz novos ramos a serem estudados e após 
incessantemente dissecados e compreendidos, produzem novos ramos sobre si mesmo num processo que não se esgota.

\section{Análise e Discussão dos Resultados}

A questão proposta aos professores é uma hipótese de proposta para elaboração de objetivos de um projeto de Educação Ambiental formulado pelos Docentes. Com esta questão, esperou-se obter indicações que contribuíssem para a formação das representações sociais dos professores da escola onde foi aplicada a pesquisa. Todos os Docentes pesquisados responderam a questão e todas as respostas possuem elementos que foram usados para a formação das categorias para análise.

A questão provocou, junto aos Docentes, a emersão de quatro categorias de análise que são fundamentais para expressar as representações sociais que têm relação direta com a Educação Ambiental: a "Ambiental", citada por $60 \%$ dos participantes e com frequência de 07 ocorrências; a "Cultural", citada por $50 \%$ dos participantes e com frequência de 08 ocorrências; a "Ação Pedagógica", citada por $60 \%$ dos participantes e com frequência (número de ações) de 13 ocorrências; e "Lixo", citada por $30 \%$ dos participantes e com frequência de 04 ocorrências. Pondera-se que há itens que formam mais de uma categoria, como por exemplo na resposta dada pelo D8 "coleta seletiva" - essa resposta foi agrupada nas categorias "Lixo" e "Ação Pedagógica".

Os recortes das respostas obtidas com a questão: "Imaginemos que a escola (comunidade escolar) busque sua ajuda para elaboração de uma atividade sobre Educação Ambiental junto aos alunos. O que você proporia como objetivo(s)?', foram:

D1: "Gastos/consumo de combustíveis dos automóveis".

D2: "Conscientizar os alunos (...) produção de lixo (...) cuidado com o planeta".

D3: “...horta comunitária”.

D4: “...problemas ambientais (...) enchentes, deslizamentos (...) despertar a consciência de que muitas vezes nós, seres humanos, somos os responsáveis".

D5: "Compreender que a conservação do meio ambiente é responsabilidade de todos".

D6: "Desenvolver a consciência ecológica e ambiental. Compreender a importância do meio ambiente...".

D7: "Os cuidados com o lixo: redução, reaproveitamento e reciclagem do mesmo (...) lixo".

D8: "Despertar a consciência ambiental. Fazer a coleta seletiva". 
D9: “... abordar durante o trabalho: queimadas, desmatamento, preservação, água".

D10: "... meio ambiente saudável".

A primeira categoria analisada foi a "Ambiental". Segundo Reigota (2010), os professores podem possuir entendimentos diversificados sobre "meio ambiente" ou ainda por "ambiente" (conforme dados coletados junto aos Docentes). Este fato levou à uma análise mais aprofundada da estrutura e das relações que essas expressões possuem no conteúdo colhido, ou seja, "a unidade de contexto serve de unidade de compreensão para codificar a unidade de registro e corresponde ao segmento da mensagem" (BARDIN, 2016, p. 137).

Expressamente manifestada pelos D2, D4, D5, D6, D8 e D10, o que corresponde a $60 \%$ dos participantes da pesquisa e com uma frequência de 07 ocorrências, a categoria Ambiental traz, a partir de seu contexto, variações em seu sentido pois "a relação com o meio ambiente é eminentemente contextual $e$ culturalmente determinada" (SAUVÉ, 2005, p. 319). A partir do contexto que orienta a formação dos entendimentos dos professores, meio ambiente pode significar: a natureza; um recurso que se pode gerir e compartilhar; um problema sobre o qual se deve orientar a atenção para prevenir ou resolver; um sistema organizado que precisa ser compreendido e sobre o qual são tomadas decisões; um lugar de pertencimento; a biosfera; um projeto societário, entre outros sentidos que podem ser formados de meio ambiente, dependendo de como pensam os sujeitos (SAUVÉ, 2005).

Quanto aos objetivos que um projeto sobre Educação Ambiental deva possuir, para os D2 e D6 o meio ambiente deve ser trabalhado por conta de sua importância, sem maiores explicações, ou seja, "é importante para quê?". Ao dizerem que o meio ambiente é importante mas não darem o sentido da importância, esses Docentes indicam a naturalização do discurso sobre aquilo que se está falando, o que forma uma barreira para o questionamento e a entrada de novos entendimentos para haver o debate e, assim, podem surgir novas reorientações do que se pensa sobre meio ambiente. Para esses Docentes há uma obviedade no conteúdo da fala que não precisa ser comentada. A sedimentação no entendimento de que o meio ambiente é um tema de importância em si, além de evidenciar a forte sedimentação que este tema ganhou no meio social onde foram coletados os dados para a pesquisa, exige também do pesquisador que estuda as representações sociais, a percepção, a sensibilidade intelectual e afetiva.

Para os D6 e D8 um projeto de Educação Ambiental para alunos do ensino fundamental precisaria ter como objetivo a formação de uma consciência ambiental. A Agenda 21 incorporou algumas diretrizes presentes na conferência de Tibilisi, algumas das quais são comentadas por Oliva (2000), quando trata do espaço que abre para citar a consciência ambiental como elemento presente da Educação Ambiental no ensino fundamental. Os Docentes entendem que "o ensino é também essencial para conferir consciência ambiental e ética, valores, 
atitudes técnicas de comportamento em consonância com o desenvolvimento que deve abordar a dinâmica do meio físico / biológico" (OLIVA, 2000, p. 10). No entanto, a ideia de consciência ambiental pode levar os sujeitos a formarem suas ideias a partir de uma, entre duas posições antagônicas. A primeira, é de que a Educação Ambiental pode assumir um papel conservador, de manutenção dos valores e comportamentos sociais já presentes no meio social sem, de fato, chegar à raiz das questões socioambientais e, com isso, corroborar para a perpetuação dos interesses dominantes. A segunda possibilidade é a de que a consciência ambiental possa provocar um comprometimento com a "renovação cultural, política e ética da sociedade e com o pleno desenvolvimento das potencialidades dos indivíduos que a compõem" (LIMA, 2009, p. 152).

Para o D4 a questão ambiental se relaciona à percepção dos problemas de ordem geofísica cuja causa, para o pesquisado, se encontra diretamente ligada à ação do homem sobre o mundo natural, ou seja, a ação antrópica. Com o uso de instrumentos (maquinação do mundo natural) a ação humana redimensionou o espaço e o tempo, produzindo uma relação artificial e distante do meio ambiente natural, dando origem à era do desequilíbrio natural.

A história formada da relação do homem com o mundo natural revela-se, na fala do D4, como problemático, que não está dando certo, que possui consequências indesejáveis. Afirma Freire (2000, p. 20), "a história que se processa no mundo é aquela feita pelos seres humanos". Segundo Bigliardi e Cruz (2008), a exploração descomedida dos recursos naturais para atender a expansão do sistema de produção capitalista, o crescimento populacional e o aumento do consumo fizeram com que a relação que o ser humano possui com o meio ambiente chegasse a seu esgotamento. Portanto, o modelo societário que possuímos não apresenta mais condições de se manter.

Identificado o problema, o D10 afirma que um dos objetivos da Educação Ambiental deve ser contribuir (de forma positiva) com o meio ambiente, sair da estagnação para ações objetivas de mudança de postura para a formação de uma nova história. Já o D5 especifica sua posição sobre o objetivo que deve ser trabalhado em Educação Ambiental para contribuir com o meio ambiente e para a conservação ambiental. A complexidade, a força do entorno econômico e político que atinge o debate sobre Educação Ambiental leva alguns autores a desconsiderar algumas práticas pontuais feitas pelos professores ao longo de sua jornada de trabalho como de fato ações de Educação Ambiental.

A segunda categoria que emerge das respostas dos D2, D4, D5, D6 e D8 é a categoria Cultural. Segundo essa categoria, a Educação Ambiental é um "processo voltado para o desenvolvimento do estímulo à sensibilidade e às vivências emocionais, à abertura para a alteridade e a diversidade e a valorização de outros saberes complementares ao saber científico" (POCHO, 2011, p. 55). 
A formação dessa categoria se deu com a junção de três grupos semânticos convergentes. O primeiro está diretamente ligado à ação de "conscientizar" (D2, D4, D6 e D8), o segundo, possui referência a ação de "compreender" (D5 e D6) e o terceiro atribui senso de cooperação coletiva com a "responsabilização" social sobre as questões ambientais (D4 e D5). De posse desses dados, obteve-se o resultado de uma participação de $50 \%$ dos pesquisados nesta categoria e uma frequência igual a 08 .

A categoria cultural é uma representação social que possui um impacto muito relevante no entendimento dos professores da escola pesquisada. Para esses professores, a disseminação da conscientização, a compreensão e a responsabilidade são a essência do processo educativo em Educação Ambiental. Segundo Pocho (2011), a Educação Ambiental voltada para a formação de valores possibilita a criação ou ampliação dos laços de pertença a um grupo social cujas representações sociais permitem sua identificação. Neste sentido, a categoria culturalista é a formação de uma identidade a partir de valores socialmente construídos e comunicados pela prática da educação escolar. A cultura possui sua importância por possibilitar um entendimento, uma orientação para o ser humano se relacionar com seus pares e com o mundo natural. Ao se falar da importância da cultura na construção de significados, é preciso ter claro que

Damos significados às coisas através da forma como as representamos, e esses significados estão sendo constantemente produzidos em diversos lugares e práticas sociais. [...] é notável a produção de significados em tão grande escala e velocidade nos dias de hoje, visto que os modernos meios de massa têm capacidade de produzir e difundir significados globalmente, alterando de forma crucial os relacionamentos já estabelecidos entre espaço-tempo. A representação cultural é uma das formas mais eficazes de instituição de significados [...] (KINDEL, 2003, p. 225).

A cultura é um meio para disseminação e assimilação dos contextos sociais e a escola é uma das principais instituições colaboradoras nesse processo. Apesar do "ar" de neutralidade dos conhecimentos escolares, eficiência na inculcação dos conteúdos, valores e comportamentos indispensáveis à vida social, e depuradora da natureza humana tendenciosa ao mal, a escola respira esse "ar" e parte para uma Educação Ambiental de tendência culturalista. Dessa forma, pode acabar por perpetuar as infraestruturas sociais, econômicas e políticas incompatíveis com uma educação crítica no campo ambiental. A Educação Ambiental pode acabar ficando na superficialidade de ações pouco relevantes para a superação da crise ambiental e com o peso da culpa pelos efeitos que a depredação do meio ambiente natural tem provocado. A categoria Culturalista 
busca por mudança cultural e individual como suficiente para gerar desdobramentos sobre a sociedade e como forma de aprimorar as relações sociais, tendo como parâmetro as relações vistas como naturais, sem entrar no mérito a possibilidade histórica de construir outro sistema social, adotando geralmente uma abordagem funcionalista de sociedade e organicista de sociedade e organicista de ser humano (POCHO, 2011, p. 52).

Para Guimarães (2004), a vertente de pensamento em Educação Ambiental que se pauta na reprodução de valores e comportamentos previamente estabelecidos, os quais são considerados como produto de uma reflexão sobre as questões ambientais sustenta a ideia de individualização da responsabilidade sobre os problemas ambientais.

No entanto, a perspectiva de Educação Ambiental culturalista pode ser adaptada com a participação dos alunos num exercício reflexivo para a construção de autonomia em lugar da heteronomia imposta por "sabichões" que sabem o que é certo fazer. Pode ser o início de uma reflexão sobre as questões ambientais no ensino fundamental para posteriormente se adentrar em questões de maior exigência cognitiva como a política e a economia. Neste caso, os professores precisariam ter claro que a Educação Ambiental culturalista e participativa seria uma etapa no processo para se chegar a uma Educação Ambiental crítica e emancipatória. Reconhece-se que não é o caso encontrado nos dados coletados nesta pesquisa. Os Docentes pesquisados limitam-se a apresentar a Educação Ambiental culturalista como estratégia para a Educação Ambiental na escola onde atuam.

A terceira categoria é uma ramificação da macrocategoria categoria "preservacionista". Dada a característica de elencar temas para serem trazidos para a construção de uma espécie de currículo em Educação Ambiental, essa categoria, na análise dessa questão, será denominada de "Ação Pedagógica", formada pelas respostas de D1, D3, D4, D7, D8 e D9. Ressalva-se que, em outro momento, essa categoria poderá ser tratada como "preservacionista", macrocategoria cuja "ação pedagógica" pertence. Esta categoria foi formada a partir das indicações de temas e ações que os professores propuseram em suas respostas, desde que não tivessem vinculação direta com a categoria culturalista, anteriormente trabalhada.

Para os Docentes, na hipótese de um projeto sobre Educação Ambiental, os objetivos deveriam trazer em seu conteúdo assuntos e práticas que variam da poluição do ar (D1); fazer uma horta comunitária (D3); tratar sobre enchentes e deslizamentos (D4); reduzir, reaproveitar e reciclar o lixo (D7); promover a coleta seletiva (D8); além de, como expressou o (D9), tratar das queimadas, desmatamento, preservação, água, entre outros temas. 
De acordo com D3, o principal objetivo de uma proposta de projeto em Educação Ambiental seria fazer uma horta comunitária. Este objetivo não estaria restrito ao ambiente escolar, pois envolveria também a comunidade, o que estreitaria os laços da escola com seu entorno. Apesar deste ponto positivo favorecer aspectos sociais relevantes, fazer uma horta comunitária seria uma ação pontual carente de uma organização teórica e metodológica relevantes para a formação crítica e cidadã.

A realização de trilhas, hortas, palestras, plantio de árvores, confecção de cartilhas, jogos e vídeos, enquanto praticada isoladamente como atividade educativa é importante; porém, deixa de atingir os objetivos maiores da Educação Ambiental se dissociada de um processo que exige planejamento contínuo de construção de conhecimentos, de formação de atitudes e de desenvolvimento de habilidades que resultem em práticas sociais positivas e transformadoras (PHILIPPI Jr.; PELICIONI, 2002, p. 05).

Neste sentido, ter a horta comunitária como principal objetivo para um projeto sobre Educação Ambiental, pode resultar no estabelecimento de uma distância da crítica social e uma Educação Ambiental voltada para práticas individualizadas voltadas para a ação de uma disciplina ou de um professor.

Portanto, para haver transformações significativas, não bastam apenas mudanças individuais (partes), mas necessitam-se também mudanças recíprocas na sociedade (todo). Isso para que haja nas duas situações, indivíduos e sociedade, ampliação das possibilidades de transformações potencializando mudanças de curso e criando opções a um caminho único predeterminado por uma proposta dominante de sociedade e seu modelo de desenvolvimento (GUIMARÃES, 2007, p. 89).

Ao encontro do que reflete Guimarães (2007), a horta comunitária, pode ser o estopim que resulte em uma organização sistemática de um plano de ações que provoque a saída da superficialidade para um mergulho mais profundo nas estruturas que determinam o fazer social. "Mesmo aquelas (escolas) que já se encontram em um nível mais elevado de estruturação de uma política de Educação Ambiental, necessitam aprimorar e intensificar os meios de comunicação com a sociedade" (MENDONÇA, 2015, p. 167).

Segundo o D4, a ação pedagógica deve ter por objetivo fazer a relação entre os problemas ambientais como enchentes e deslizamentos com a ação antrópica, e trazer este problema para a sala de aula. Segundo os economistas Saes e Romeiro (2014, p. 26), 
dessa compreensão os economistas ecológicos destacam a propriedade de resiliência dos ecossistemas que torna não lineares as reações dos mesmos aos impactos que sofrem. Em sistemas complexos esta não linearidade torna imprevisível o risco de ruptura ecossistêmica, que pode ser irreversível e potencialmente catastrófica.

A ação predatória do ser humano sobre os ecossistemas pode provocar mudanças irreparáveis na linearidade de recuperação da natureza. A própria natureza não se autorepara de forma adequada, levando a mudanças de paisagens, processo de desertificação de regiões antes produtivas, extinção de espécies, epidemias, falta de recursos para a vida, destruição de bens móveis e imóveis, migração climática, enfraquecimento das relações políticas e econômicas.

\begin{abstract}
Em termos de bem-estar humano, a mudança climática pode representar uma ameaça superior a qualquer outra mudança ambiental. Isso se deve a seu caráter irreversível, a sua escala espacial global e a sua combinação com fatores sociais e ecológicos que lhe atribuem certo grau de incerteza em relação à magnitude e tendência dos seus impactos. As evidências apresentam diversos riscos associados aos choques climáticos, como a mortalidade e morbidade por eventos extremos, deslocamentos de populações e aumento da incidência de malária e de doenças de veiculação hídrica (MACANA, 2008, p.19).
\end{abstract}

Para D7, a ação pedagógica sobre Educação Ambiental deve proporcionar aos alunos conhecimentos e práticas voltadas para a redução, reaproveitamento e reciclagem do lixo. Próximo desse entendimento, o D8 afirma que é preciso ter como objetivo a orientação sobre a coleta seletiva do lixo produzido.

A reciclagem e a reutilização são elementos que estão diretamente ligados à visão preservacionista de Educação Ambiental. Quando tratam sobre a questão ambiental, o senso comum e os meios de comunicação apontam a reciclagem como principal cuidado e boa prática. Esta tendência entra no ambiente escolar com propostas diversificadas que variam de coleta de latinhas e óleo de cozinha que são encaminhados para empresas de reciclagem e gerar renda para escola, até a reutilização de materiais para fazer brinquedos ou outros produtos. 
Já por muitas décadas, as discussões sobre a utilização dos recursos naturais pelo homem, vêm sendo alvo da preocupação dos professores. Em nome disso, projetos de Educação Ambiental compõem anualmente os planejamentos de ensino. Resultam em ações que visam conscientizar os alunos ao uso correto da água, ao destino correto do lixo, incentivam a reciclagem e economia de bens que utilizam em sua fabricação recursos naturais findáveis, como por exemplo, a luz elétrica ou utensílios fabricados a partir de petróleo. Outros, não sabedores de que hoje a maioria do papel produzido origina-se de reflorestamento de Pinus e/ou Eucalipto, encorajam a economia de papel acreditando que seu desperdício pode gerar desmatamento e por isso, também incentivam o plantio de árvores nativas e visitação a parques e reservas ambientais visando à conscientização ecológica (AVILA; LINGNAU, 2015, p.146-147).

Presente no discurso dos Docentes pesquisados, na aplicação de um projeto por uma empresa privada no ambiente escolar público, nas publicações de pesquisadores e no senso comum, o projeto de Educação Ambiental escolar que apresenta como objetivo a redução, o reaproveitamento, a reciclagem e a coleta seletiva em "lixeiras coloridas" (D8), vai ao encontro de representações sociais que extrapola os limites de um grupo específico de professores e atinge um ideário coletivo mais amplo das práticas em Educação Ambiental no Brasil.

Diante do que foi analisado sobre práticas educativas que trabalhariam a questão ambiental a partir da redução, da reciclagem, do reaproveitamento e da coleta seletiva do lixo, pode-se concluir que esta perspectiva de Educação Ambiental se esforça por adequar os indivíduos a uma forma de ser socialmente correta em sua manifestação cotidiana. Busca-se assim não sair da superficialidade do alcance do indivíduo.

A terceira categoria é finalizada com os objetivos para um projeto em Educação Ambiental apresentados por D9: "Queimadas, desmatamentos, preservação, água...". Ao aproximar esses itens sem descrevê-los, o D9 nos leva a entender que a Educação Ambiental deve tratar de forma genérica as questões que mais estão presentes no senso comum como causas do mal-estar presente na sociedade por conta de ações prejudiciais ao meio ambiente. $O$ pensamento ecológico somente passa a tomar maior volume na fala do D9 quando traz subjacentes à sua fala o conteúdo de preocupação com o esgotamento dos recursos naturais e a defesa de uma posição preservacionista cuja proposta é a distância do ser humano da natureza que ainda permanece imaculada. $O$ trabalho pedagógico alarmista dos problemas ambientais aproxima-se das práticas tradicionais de ensino que valorizam a assimilação de conteúdos e despreza a crítica política. 
A quarta categoria é a "Lixo", expressa pelos D2, D7 e D8. Essa categoria apresentou frequência 04 nas respostas à questão. Além das respostas dadas à questão, serviram ao propósito da análise dessa categoria os conteúdos coletados na observação de campo. Optou-se pela formação dessa categoria em separado de outras aqui estudadas pelo fato dela possuir uma presença diferenciada no contexto escolar pesquisado. O lixo é um dos temas mais comuns no contexto da prática pedagógica dos professores participantes da pesquisa.

Com os dados obtidos na observação da aula do D7, no dia 09 de novembro de 2016, percebeu-se que os mesmos conteúdos apresentados como proposta na hipótese da elaboração de um projeto sobre Educação Ambiental, ou seja, o lema "reduzir, reaproveitar e reciclar" o lixo, foram utilizados para falar aos alunos sobre a responsabilidade individual que se deve ter para com o meio ambiente.

Após responder ao questionário, o docente (D1) comentou sobre uma ação que a escola promovia para a redução do desperdício dos alimentos fornecidos aos estudantes a título de "merenda escolar", o projeto "Prato Limpo". Os estudantes deveriam pegar somente o suficiente para sua saciedade, sem sobras. Outra ação que a escola possuía era a coleta de óleo de cozinha peneirado para a produção de sabão, que não deu certo pelo fato de o óleo de cozinha vir com resíduos e "os professores não terem tempo para organizar tudo".

Mesmo não tendo dado indicações da categoria "lixo" em suas respostas à questão, os docentes D1, D4 e D6 a compreendem como importante na prática pedagógica escolar cotidiana. Ou seja, a representação social do conteúdo "lixo" aos objetivos da Educação Ambiental se manifesta de forma espontânea nas falas dos professores e no concreto da vida escolar que se manifesta à sociedade.

Com o panorama produzido a partir dos conteúdos coletados e que formaram a categoria "lixo", os Docentes da Escola onde ocorreu a pesquisa compartilham a representações sociais do cuidado com o meio ambiente a partir do destino adequado ao material produzido após o consumo. A Educação Ambiental para esses docentes se caracteriza pelo pragmatismo acrítico cujo proposta se alinha a uma Educação Ambiental conservadora.

A observação de campo indica que o trabalho dos professores é orientado para temas como: a reciclagem, a reutilização e do reaproveitamento de materiais. Temas esses que estão presentes no cotidiano na vida escolar. 


\section{Conclusões}

Sob a luz da Teoria das Representações Sociais, a pesquisa teve como objetivo proceder o levantamento e a análise das representações sociais junto aos professores de uma escola pública de ensino fundamental na cidade de Joinville - SC quanto aos "objetivos que devem ser trabalhados na Educação Ambiental'.

Os conteúdos ligados à temática ambiental que emergem nas relações sociais do mundo do trabalho docente são muito importantes pelo fato de estarem imbricados com a prática educacional manifestada no cotidiano da escola. Neste sentido, as categorias representacionais manifestadas pelos professores da escola onde a pesquisa foi aplicada atuam ao mesmo tempo como produto social e possibilidades formadoras do pensamento dos demais agentes, em especial dos alunos. E isto acontecendo a partir da sistematização das práticas pedagógicas ou do simples convívio que se dá no senso comum.

Em vista do objetivo que se propôs alcançar e dos resultados obtidos com a execução do estudo, reconhece-se que a pesquisa obteve êxito. As representações sociais que emergiram com este estudo apontam para um vasto mosaico, composto por diversas categorias que foram se formando ao longo das análises e que sine qua non o fenômeno humano seria entendido como um monobloco rígido e frio movido a uma só perspectiva. O pulsar da vida se manifesta nas representações sociais que os professores deixaram que a fluidez da pesquisa captasse. $O$ maior valor que esta pesquisa obteve foi trabalhar uma fração da manifestação da vida dos professores na escola, campo onde o estudo se desenvolveu.

Os principais conteúdos manifestados pelos professores quanto ao meio social escolar permitiram compreender a formação de uma parcela do real, comunicado e retroalimentado por respostas às questões propostas, expresso nas falas, manifestado nos projetos pedagógicos da escola, os quais, como se lê em Moscovici (2015), não só revelam como o mundo é entendido mas, como ele é formado, haja vista que os sujeitos são formados pelas representações sociais presentes no meio social em que vivem. E mais, presentes nas ações que formam a sociedade na medida em que atuam ativamente nela.

As categorias que emergiram desse estudo demostram que o não há uma única forma para se pensar os objetivos para um projeto em Educação Ambiental. As representações sociais dos professores que participaram do estudo apresentam um viés muito forte na Educação Ambiental conservadora, entendida como uma vertente que valoriza a ação do ser humano sobre o ambiente natural, dando valor a livre iniciativa e provocando a formação de ações responsáveis sobre o meio ambiente, mas despreza-se a macroestrutura social e econômica, fatores que perpetuam o estado de exploração da natureza. Nessa posição, acontece uma profunda contradição enraizada em suas bases ao entender, como se lê em Reigota (2014), que ser humano pode transformar sua realidade por iniciativas particulares, focais e minimamente 
impactantes sem considerar os fatores políticos, sociais e econômicos subjacentes ao agravamento da crise ambiental.

\section{Referências}

AVILA, A.M., LINGNAU, R. Crise ambiental, ensino de biologia e Educação Ambiental: uma abordagem crítica. Revista Monografias Ambientais Santa Maria, v. 14, n. 2, mai-ago. 2015 p. 137-150. Revista do Centro de Ciências Naturais e Exatas - UFSM.

BARDIN, L. Análise de conteúdo. São Paulo: Edições 70, 2016.

BIGLIARDI, R.V.; CRUZ, R.G. Currículo escolar, pensamento crítico e Educação Ambiental. Revista eletrônica Mestrado em Educação Ambiental. Rio Grande, v. 21, p. 332-340, jul/dez. $2008 . \quad$ Disponível em:<https://www.seer.furg.br/remea/article/view/3073>. Acesso em: 19 outubro/ 2017.

FREIRE, P. Política e educação: ensaios. São Paulo: Cortez, 1997.

FREIRE, P. À sombra desta mangueira. São Paulo: Olho d'água, 2000.

GUIMARÃES, M. Educação Ambiental Crítica. In: LAYRARGUES, P. P. (Coord.). Identidades da Educação Ambiental brasileira. Brasília: Ministério do Meio Ambiente, Diretoria de Educação Ambiental, 2004.

GUIMARÃES, M. Educação: participação para além dos muros da escola. In: Vamos Cuidar do Brasil: conceitos e práticas em Educação Ambiental na escola. Brasília: MEC, 2007.

INSTITUTO BRASILEIRO DE GEOGRAFIA E ESTATÍSTICA - IBGE. Cidades, 2015. [online]. Disponível em <https://cidades.ibge.gov.br/xtras/ perfil.php?codmun=420910 >. Acesso em: 19 outubro/2017.

JOVCHELOVITCH, S.; GUARESCHI, P.A. (org). Textos em representações sociais. I prefácio Serge Moscovici I. - $2^{\underline{a}}$ ed. Petrópolis, Rio de Janeiro: Vozes, 1995.

KINDEL, E.A.I. A natureza no desenho animado ensinando sobre homem, mulher, raça, etnia e outras coisas mais. 2003. Tese (Doutorado) - Universidade Federal do Rio Grande do Sul, Faculdade de Educação, Programa de PósGraduação em Educação, Porto Alegre, RS, 2003.

LIMA, G.F.C. Educação Ambiental crítica: do socioambientalismo às sociedades sustentáveis. Educação e Pesquisa, São Paulo, v.35, n.1, p. 145-163, jan./abr. 2009.

MACANA, E.C. Impactos potenciais da mudança climática no desenvolvimento humano: uma análise baseada na abordagem das capacitações. 2008. $241 \mathrm{f}$. Dissertação (mestrado em economia) - Universidade Federal do Rio Grande do Sul, Porto Alegre. 2008. 
MENDONÇA, M.G. Educação Ambiental no município de Urbelância (MG): reflexões sobre a práxis e sua relação com o processo de planejamento em gestão ambiental. 2015. Tese (Doutorado) - Universidade Federal de Uberlândia, Programa de Pós-Graduação em Geografia, Uberlândia, MG, 2015.

MOSCOVICl, S. Representações sociais: Investigações em psicologia social. 11. ed. Petrópolis: Vozes. 2015.

OLIVA, J. Textos da saúde Educação Ambiental para o Salto para o Futuro. Brasília: SEF/SEED/MEC, 2000.

PHILIPPI, J.A.; PELICIONI, M.C.F. Alguns pressupostos da Educação Ambiental. In: PHILIPPI JUNIOR, A.; PELICIONI, M.C.F. (editores). Educação Ambiental: desenvolvimento de cursos e projetos. São Paulo: Universidade de São Paulo. Faculdade de Saúde Pública. NISAM: Signus Editora, 2002.

POCHO, C.L. Avaliação de programas governamentais de Educação Ambiental: um caso de empresa estatal da área de energia. 2011, $419 \mathrm{f}$. Tese (doutorado em engenharia de produção). Universidade Federal do Rio de Janeiro, Rio de Janeiro, 2011.

REIGOTA, M. O que é Educação Ambiental. São Paulo: Brasiliense, 2014.

SAES, M.B.; ROMEIRO, A.R. Economia ecológica e macroeconomia ecológica: uma visão geral. In: Boletim da Sociedade Brasileira de Economia Ecológica (ECOECO). № 34/35, p. 25-31. Rio de Janeiro: Janeiro a Dezembro de 2014.

SAUVÉ, L. Educação Ambiental: possibilidades e limitações. Educação e Pesquisa, São Paulo, v. 31, n. 2, p. 317-322, maio/ago. 2005. 